\title{
Analogy use in naturalistic settings: The influence of audience, emotion, and goals
}

\author{
ISABELLE BLANCHETTE \\ Birkbeck College, London, United Kingdom \\ and \\ KEVIN DUNBAR \\ Dartmouth College, Hanover, New Hampshire
}

\begin{abstract}
The ways in which analogy was used in a nonexperimental environment-politics-was investigated. We used the framework developed in analogy research to analyze the selection of analogical sources in political discourse. We took all the analogies reported in newspapers during the final week of a referendum campaign in Canada and analyzed the features of the different analogies used. We identified 234 analogies and analyzed the range over which analogies were used, semantic categories of analogies, goals of the analogizer, and emotional connotation of the analogies. Our results reveal that analogy was frequently used, that over two-thirds of the analogical sources were nonpolitical, and that many of the sources had strong emotional connotations. Furthermore, the goal of the analogizerinfluenced the selection of sources. We conclude that characteristics of the audience and emotionality of the source analog are important features in the selection of source analogs.
\end{abstract}

Research has demonstrated that analogical reasoning is an important component of human cognition that is used in virtually all domains (e.g., Dunbar, 1997; Holyoak \& Thagard, 1995; Vosniadou \& Ortony, 1989). Analogy is generally defined as the importation of knowledge from a well-known source onto a less-well-known target by the establishment of correspondences between the two. Carefully controlled laboratory studies carried out over the past 20 years have provided detailed accounts of the cognitive mechanisms involved in making an analogy (e.g., Gentner \& Markman, 1997; Holyoak \& Thagard, 1997; Wharton, Holyoak, Downing, \& Lange, 1994). Much less is known about the ways that analogy is used in nonexperimental contexts. In this paper, we investigate the way that analogy was used in a political debate. Our goal was to determine whether the types of constraints that have been identified in the cognitive laboratory also govern naturalistic uses of analogy and whether analogy use in naturalistic contexts suggest further constraints on the mechanisms underlying analogy use.

The few studies conducted on the use of analogy in political reasoning suggest that it may be an important com-

This research was funded by NSERC Grant OGP0037356 to K.D., and by an FCAR graduate fellowship to I.B. We thank Maude-Annie StLaurent, Julie Caouette, and Sylvain Sirois for their help in coding the data, and Chris Schunn, Bobbie Spellman, and David Klahr for comments on a previous version of this manuscript. We also thank Dedre Gentner, John Hummel, Richard Marsh, and one anonymous reviewer for their helpful comments on the manuscript. Correspondence should be addressed to K. Dunbar, Department of Psychological \& Brain Sciences, Dartmouth College, Moore Hall, Hanover, NH 03755 or Isabelle Blanchette, Department of Psychology, Birkbeck College, University of London, Malet Street, London, WC1E 7HX, England (e-mail:kevin.n. dunbar@dartmouth.edu or i.blanchette@psychology.bbkac.uk). ponent of political discourse, reasoning, and decision making. A number of researchers have argued that analogy and metaphor play an important role in U.S. foreign policy decision making (Gilovich, 1981; Khong, 1992; Shimko, 1994). Detailed analyses by Lakoff, Johnson, and Rohrer (Lakoff, 1991, 1993; Lakoff \& Johnson, 1987; Rohrer, 1991, 1995) suggest that metaphors have a considerable effect on how political problems are framed and understood. Voss, Kennet, Wiley, and Schooler (1992), studied the American Senate debates over the Persian Gulf Crisis in 1991 and found that senators used metaphors to present the premise of their reasoning.

In this study, we look at the factors that influence the selection of source analogs in political persuasion. We investigated the types of analogies politicians use, and the types of sources used in relation to the target, goals of the analogizer, and emotional connotation of the source. Most of the research on analogy has focused on how people retrieve and map analogies. Here we are interested in the types of source analogs that politicians and journalists select in relation to a target problem. Although the process of source selection itself has rarely been looked at, other lines of research on analogical reasoning do offer some suggestions concerning the constraints that might be placed on source selection. Two important factors should influence the selection of source analogs: similarity and goals. In addition, we also wanted to investigate the effect of emotion as emotion appears to be an important factor in political debates (Glaser \& Salovey, 1998).

\section{Superficial and Structural Similarity}

In order to generate an analogy, a source must first be retrieved from memory. Many studies have shown that 
the process of analogical retrieval is constrained by superficial similarity (Gentner, Rattermann, \& Forbus, 1993; Gick \& Holyoak, 1980; Keane, 1987; Ross, 1989). There are two levels at which analogical source and target can be similar-superficial similarity (similarity in object features) and structural similarity (resemblance in the underlying relations between the objects in the source and the target). People are more likely to retrieve a source analog that is superficially similar to the target problem than an analog that shares only structural similarity with the source (Gentner et al., 1993; Gick \& Holyoak, 1980; Keane, 1987).

Retrieval may not directly determine source selection. In the generation of an analogy, a source may be retrieved and then dismissed. Forbus, Gentner, and Law's (1994) MAC/FAC model captures this distinction. The model postulates that retrieval is mostly constrained by superficial similarity, but that the selection of a source analog will ultimately rest on its structural correspondence with the target problem. Empirical data also show that evaluation of source analogs is based on structural correspondence (Gentner et al., 1993). Source analogs taken from the same domain are likely to share object features. This superficial similarity should facilitate retrieval. This would lead us to expect that, in politics, retrieving other political problems as source analogs should be relatively common. However, selection within this set of sources should ultimately be based on structural similarity. This is the case for analogy use in science. In his investigation of scientists' reasoning, Dunbar $(1995,1997)$ found that most of the analogies used were within domain.

\section{Pragmatic Constraints}

Another dimension that the literature would predict should have an effect on source selection is the goal of the person making the analogy (Spellman \& Holyoak, 1993, 1996). To date, research on pragmatic constraints has mostly focused on how goals can affect analogical reasoning once a source is selected, for instance, in the mapping or evaluation stages. Here we are interested in how these pragmatic considerations could affect selection of a source analog. Dunbar (1995) found that scientists tended to use analogies that were from nonscientific domains when explaining a concept to a less specialized audience. On the basis of Dunbar's (1995) analysis of scientists' use of analogy, it may be hypothesized that when analogizers are addressing a general audience unfamiliar with the target topic, they will use sources from other domains.

\section{Emotion}

One further aspect of analogical reasoning that we wanted to investigate has received less attention in the literature: the role of emotion in analogical reasoning. Exceptions to this include Thagard's discussion of analogical reasoning and the generation of emotions (Holyoak \& Thagard, 1997; Thagard \& Shelley, in press), and Edwards and Clevenger's (1990) investigation of how emotion affects the ability to generate metaphors. In this study, we investigate this issue by examining the emotional con- notation of the source analogs used. Research in political psychology has noted that politicians frequently attempt to induce an emotional state in their audience (Kristiansen \& Zanna, 1994). This suggests that emotional connotation could be an important feature in the selection of a source analog used in a heated political debate.

To look at all these different issues, we examined analogies in relation to a specific political debate: the Quebec referendum of 1995. The Canadian province of Quebec held a referendum on October 30, 1995 to determine whether Quebec should separate from the country of Canada and become an independent country or whether it should stay part of Canada. The province of Quebec is where the majority of the French-speaking population of Canada resides. Voters had the choice of voting "yes" for becoming a new country, or "no" for staying in Canada. The political campaign was divided into the "yes" side and the "no" side. Both sides campaigned extensively and the "no" side won by the slimmest of majorities (51\%).

We investigated the use of analogy during the final week of the referendum campaign by searching for the use of analogies in three important Montreal daily newspapers. We decided to use newspapers as our source of analogies because newspapers reported analogies that politicians made during the campaign and those made by major commentators who wrote articles concerning the referendum in the newspapers. Although this method does not permit direct access to the cognitive processes involved in the generation of the analogies, it does allow us to analyze the outcome of complex reasoning processes as they occur in naturalistic situations.

\section{METHOD}

\section{Data}

The data set consisted of articles from the three most important newspapers in Montreal. The time period used was from October 27, 1995 until November 2, 1995. The referendum was held on October 30 . We searched a CD ROM version of each of the three newspapers using a keyword search. The keyword used was referendum .

\section{Data Analysis}

The first step of the analysis consisted of the identification of analogies. All items in which a person stated a similarity exists between $\mathrm{X}$ and $\mathrm{Y}$ and mapped a feature or features from $\mathrm{X}$ to $\mathrm{Y}$ were coded as analogies. To determine the frequency of analogy use, we counted the overall number of analogies and determined the number of articles containing at least one analogy. We further examined whether these articles were news or opinion articles. News articles were articles that reported on events in the campaign. Opinion articles were articles written by journalists and politicians that tended to attempt to persuade readers that voting a particular way was best for the province, and what the consequences of voting yes or no might be.

The analogical sources were first coded along important dimensions. The range of the analogy, defined as the semantic difference between the domain of the source and that of the target, was first coded. The source analogs were divided into those from the domain of politics (within-domain analogies) and those from domains other than politics (other-domain analogies). Because certain clusters seemed to exist, we decided to further code the sources according to the domain of knowledge they were taken from. We did not impose a set of semantic categories on these data. Instead, we took all 
Table 1

Different Source Categories Used, With Examples and Frequencies

\begin{tabular}{|c|c|c|}
\hline Source & Example & $n$ \\
\hline$\overline{\text { Politics }}$ & $\begin{array}{l}\text { "Canada will disappear as other multinational federations like } \\
\text { Czechoslovakia, Yugoslavia, and the USSR have." }\end{array}$ & $55(24 \%)$ \\
\hline Magic/religion & $\begin{array}{l}\text { "A win from the YES side would be like a magic wand for the } \\
\text { economy." }\end{array}$ & $24(10 \%)$ \\
\hline Sports & $\begin{array}{l}\text { "Québec's path to sovereignty is like a hockey game. The } \\
\text { referendum is the end of the third period." }\end{array}$ & $21(9 \%)$ \\
\hline Family/relationships & $\begin{array}{l}\text { "It's like parents getting a divorce, and maybe the parent you don't } \\
\text { like getting custody." }\end{array}$ & $20(9 \%)$ \\
\hline Medicine & $\begin{array}{l}\text { "Separation is like a major surgery. It's important that the patient } \\
\text { is informed by the surgeon and that the surgeon is impartial. The } \\
\text { referendum is a way to inform the population. But in this case the } \\
\text { surgeons are not impartial and they really want their operation." }\end{array}$ & $18(8 \%)$ \\
\hline Business & $\begin{array}{l}\text { "I know what it's like to start a new business. I knew there would } \\
\text { have been great difficulties to overcome. But I also know we } \\
\text { would have overcome them." }\end{array}$ & $16(7 \%)$ \\
\hline Geography & $\begin{array}{l}\text { "The arrival of Bouchard in the campaign was like an earthquake, } \\
\text { and the NO side had to deal with the tremors." }\end{array}$ & $13(5 \%)$ \\
\hline Transportation & $\begin{array}{l}\text { "The Parti Québécois wants to put the sovereignist train back on } \\
\text { track as fast as possible." }\end{array}$ & $11(5 \%)$ \\
\hline War & $\begin{array}{l}\text { "Except for Bouchard, all the other generals in this political } \\
\text { battle are wounded. The two armies..." }\end{array}$ & $8(3 \%)$ \\
\hline Housing & $\begin{array}{l}\text { "Québecers don't want to feel at home in the rest of Canada, what } \\
\text { they want is to build their own home." }\end{array}$ & $6(2 \%)$ \\
\hline Animals & $\begin{array}{l}\text { "Québec was force-fed a constitution down its throat, just like a } \\
\text { goose." }\end{array}$ & $5(2 \%)$ \\
\hline Other & $\begin{array}{l}\text { "If the campaign blossomed like a flower, imagine the garden we } \\
\text { will make out of Québec." }\end{array}$ & $37(16 \%)$ \\
\hline
\end{tabular}

the analogies and grouped them into sets of semantically similar domains. This grouping resulted in a total of twelve source categories: politics, magic/religion, sports, family/relationships, medicine, business, geology, transportation, war, housing, animals, and other.

Analogies were coded for their partisan nature. On the variable side, an analogy was coded as "pro yes" or "pro no" only if it clearly stated a position on the central question of the debate. Otherwise, the analogy was coded as indefinite.

Finally, analogies that had been identified as either pro yes or pro no on the variable side were further divided as a function of their goal. Analogies were coded as "support own" if they attempted to promote one's position, and as "attack other" if they challenged the opposing position.

I.B. coded the data on the following variables: range, source category, side, and goal. An independent judge coded $20 \%$ of the data (47 analogies). Interrater agreement ranged from $93 \%$ for the variable range, to $82 \%$ for goal. The agreement for source category was $87 \%$ and that for side was $85 \%$. To determine whether the sources used in these analogies had an emotional component, two coders, neither of whom had any knowledge of the analogies, were presented with all the specific sources used in the analogies. The coders had to judge whether the item had an intrinsically positive, negative, or neutral emotional connotation. The interrater agreement was $70 \%$. Only the items on which the two coders agreed were included in this analysis of connotation.

\section{RESULTS}

\section{Overall Features of Analogy Use}

We obtained 434 articles dealing with the referendum. Overall, 167 (38\%) of the articles contained at least one analogy. This proportion differed as a function of the type of article. Of the information articles, $30 \%$ contained at least one analogy; of the opinion articles, $62 \%$ contained at least one analogy. A total of 234 different analogies were identified in the data set.

A substantial majority of the analogies analyzed were other-domain analogies $(n=179,77 \%)$. These analogies used sources outside the domain of politics. Among these, the domains of knowledge most often used as analogical sources were magic/religion, sports, and family relationships. The frequency of use of each of the source categories as well as examples are provided in Table 1.

\section{Emotional Features of the Source}

As stated in the Method section, two independent coders rated the sources as positive, negative, or neutral. For this analysis, we used only the 166 analogies for which there was agreement on the emotional content. Of the 166 analogies, $40 \%(n=66)$ were judged as being intrinsically negative, $15 \%(n=25)$ as being neutral, and $45 \%$ $(n=75)$ as carrying a positive connotation.

The proportion of sources with positive, negative, and neutral emotional ratings varied as a function of the range of the analogy $\left[\chi^{2}(2, N=166)=32.89, p<.0001\right]$. As can be seen in Figure 1, other-domain analogies were more emotionally strong than were the analogies from the political domain.

\section{Differences in Analogy as a Function of Side}

We used both understanding of the analogy and knowledge about the opinions of the analogizer to break down the analogies that were clearly pro yes and clearly 


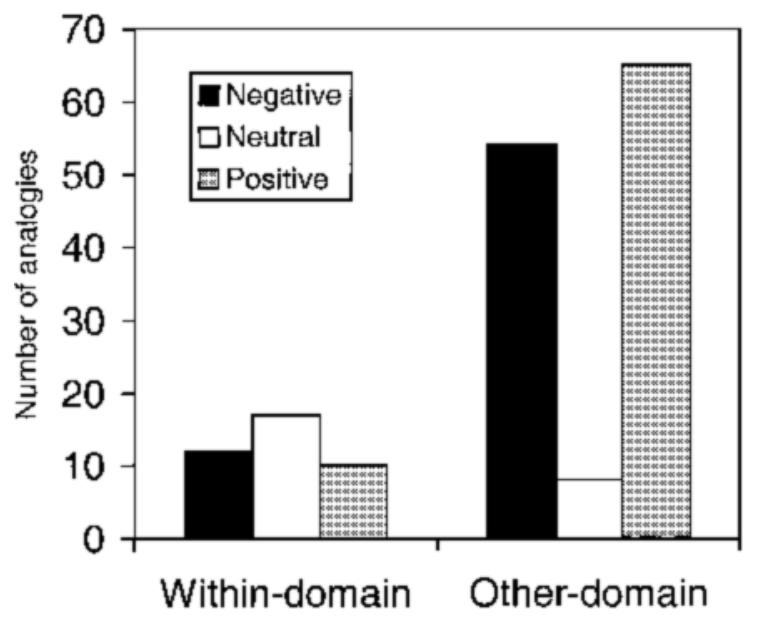

Figure 1. Emotional connotation of within- and other-domain analogies.

pro no. Many analogies $(n=94)$ were somewhat ambiguous about whether they were yes or no, and we excluded these from our analyses. These analogies were often about the way that the referendum was being conducted or about specific events during the campaign. For example, the analogy "Speaker Gilbert Parent will be hard-pressed to keep the lid on the parliamentary pressure cooker" was not coded as either yes or no. Thus, we obtained 69 analogies for the yes side and 71 analogies for the no side.

The two sides mainly used the same source categories. There was no significant difference in the source categories as a function of side $\left[\chi^{2}(11, N=140)=17.20, p>\right.$ .05]. Although the two sides used sources from the same categories, they did not use the same specific sources. For example, although both the yes and the no sides used the family domain frequently, analogies supporting the yes side often referred to the birth of a child and never to divorce, whereas the no side frequently referred to divorce and never to the birth of a child. In the entire dataset, we encountered only two cases of the use of the same specific source by both sides.

Pro no and pro yes analogies also were alike in their overall level of superficial similarity. There was no difference in the range of the analogies used by the two sides $\left[\chi^{2}(1, N=140)=0.1, p>.05\right]$. Both sides used the same proportion of within- and other-domain analogies.

We analyzed whether the yes and no sides differed in terms of emotionality. Coders agreed on the emotional dimension of 94 of the 140 analogies identified as pro-yes or pro-no. A chi square performed on the emotional connotation by side showed no significant difference $\left[\chi^{2}(2\right.$, $N=94)=3.86, p>.05]$. Thus, pro-yes and pro-no analogies used positive, negative, and neutral sources in the same proportions.

\section{Differences in Analogy as a Function of Goals}

Analogies identified as pro yes and pro no were broken down according to the goal that they were used for (support own or attack other). Forty-seven analogies were coded as support own and 69 as attack other. Of these 116 analogies, 74 had been identified as positive, negative, or neutral by our two coders. The emotional connotation of sources did vary as a function of the goal of the analogy $\left[\chi^{2}(2, N=74)=22.84, p<.05\right]$. As can be seen in Figure 2, the goal of the analogy was highly related to the emotional connotation of the source. Eighty percent of the sources used to support one's own position had a positive emotional connotation, while $60 \%$ of sources used in analogies meant to attack the opposing position had a negative emotional connotation.

The goal of the analogy, however, did not have an effect on the range or on the source categories used. There was no difference in the range of the support own and attack others analogies $\left[\chi^{2}(2, N=116)=0.27, p>.05\right]$ and no difference in the source categories used $\left[\chi^{2}(11, N=116)=\right.$ $17.51, p>.05]$.

\section{DISCUSSION}

An important finding that emerges from this study is that analogy was very prevalent in the political discourse. Furthermore, analogy was twice as frequent in opinion articles compared with news reports, indicating that analogies are frequently used in argumentative political discourse. Our findings also point toward a number of features that are important in naturalistic uses of analogy and the ways that source analogs are selected.

A large majority of the analogies contained otherdomain sources-sources taken outside the domain of politics. Analogies were based on abstract features from widely different domains. Thus, the selection of a source analog was not limited to superficially similar alternatives. Previous research has established that superficial similarity has an important influence on the retrieval of source analogs (Gentner et al., 1993; Gick \& Holyoak, 1980; Keane, 1987). However, it appears that other factors also influence the selection of analogical sources in naturalistic settings such as politics. The finding that the majority of analogies were drawn from nonsimilar domains is also different from our previous work on scientists' use of analogy. For scientists, we found that the majority of analogies were from related scientific domains rather than from vastly different domains (Dunbar, 1995, 1997). One hypothesis for this difference is that the audience that the analogizer is communicating with has an important impact on source selection. In the scientific meetings that Dunbar studied, experts were addressing other experts. All reasoners had detailed knowledge of the within-domain source analogs. In the present study, the journalists and politicians making the analogies can be considered experts in politics. However, their audience is the general population. Although it is implicit in the definition of an analogy that the source needs to be familiar, this has received little attention in the literature. Our results suggest that the audience has an important influence on the selection of source analogs. 


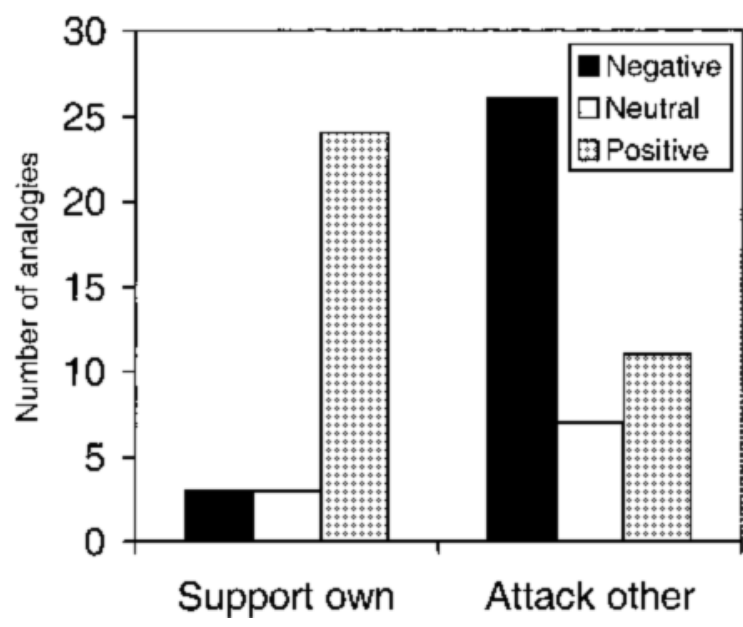

Figure 2. Emotional connotation of analogies as a function of goal.

More evidence in support of this hypothesis can be gleaned from a previous investigation of analogy use in politics. Khong (1992) studied the analogies used by politicians and strategists in their decisions concerning Vietnam. The majority of these analogies were within domain, involving comparisons to other foreign policy problems. The analogies were used during meetings where other experts were present. This contrasts with our results where politicians, addressing a general audience, drew mostly other-domain analogies.

The finding that over three-quarters of the analogies used were nonpolitical might be because the journalists who wrote the articles filtered out the analogies that were based on superficial features. We checked this hypothesis by attending a number of speeches by politicians in a recent election campaign, and compared what the politicians said with what was reported in the newspapers. The features of the analogies that were reported in the newspaper articles were not different from the analogies used at the political meetings. The same proportion of withinand other-domain analogies (approximately $25 \%$ and $75 \%$, respectively) was found for both the analogies reported and not reported in the media. Thus, it does not appear to be the case that the predominance of nonpolitical analogies is a by-product of the filtering of analogies by the newspapers.

A number of possible hypotheses can be advanced for our finding that the majority of analogs were from superficially dissimilar domains. One hypothesis is that although the majority of sources originally retrieved were superficially similar, these are most often dismissed and the few nonsuperficially similar sources retrieved end up being selected. Because we are looking at the outcome of a set of complex cognitive operations that both groups and individuals were involved in, this is potentially plausible. However, there is some experimental evidence suggesting that this might not be the case. In a series of experiments
(Blanchette \& Dunbar, 2000), participants were asked to generate source analogs in relation to a target political problem. In this type of task, few superficially similar sources were retrieved. Politicians and journalists were in a similar situation where they generated source analogs. Furthermore, it might be argued that for political speeches, the fact that the analogies may be generated by groups of speechwriters may lead to a preponderance of superficially dissimilar analogs. However Blanchette and Dunbar found no differences between groups and individuals in the relative frequencies of within- and otherdomain analogies, suggesting that this type of explanation does not account for the results of the present study.

Another possible hypothesis for the preponderance of other-domain analogies in our dataset relates to the mechanisms that are used to search memory for analogs. In our analyses, sources taken from domains other than politics are considered superficially dissimilar because the objects in the source and target are different. One type of structural similarity can exist where relations are similar and objects are different, but specific words used to describe the relations are the same (Gentner et al., 1993; Hummel \& Holyoak, 1997). In this case, key relational words could be used to search memory for a source. For instance, a politician's representation could include the proposition "Quebec should not separate from Canada." The source could include the proposition "Person X should not separate from person Y." The objects (people and country/province) are different and thus the analogs would not be considered superficially similar. Yet the presence of the same relational word such as "separate" may facilitate retrieval (Hummel \& Holyoak, 1997; Ross, 1989). This effect has been demonstrated empirically in laboratory studies conducted by Clement, Mawby, and Giles (1994). It may contribute to the retrieval of otherdomain sources such as "divorce" in the situation studied here.

The hypothesis that politicians and journalists could search memory using specific relations is consistent with the finding that expertise is important in analog retrieval. There is empirical evidence showing that experts encode information in relational terms (Ericsson \& Smith, 1991) and that in analogical reasoning contexts experts may be more likely to retrieve on the basis of structural features (Novick, 1988). In the present study, the expertise of the politicians and journalists making the analogies might contribute to the retrieval of sources that share structural, but not superficial, similarity with the target problem.

Another important feature of journalists' and politicians' use of analogy was the influence of goals. This effect appeared to be highly specific. Although there were no differences in the analogies used by the pro-yes and pro-no sides, we found that the specific goal of an analogy, whether it was to attack the other's position or support one's own, had an important impact on the emotional connotation of the analogy used. This indicates that emotion is another way through which pragmatic considera- 
tions can affect the selection of a source. Our results show that emotional connotation is related to the domain that a source is selected from. Other-domain source analogs were rated as more emotional. In addition to the audience being familiar with them, other-domain analogies, in this context, could also be of interest because they generally carry a stronger emotional connotation. Certainly, otherdomain analogies are not always more emotional. Comparisons to the Vietnam war or to Hitler are good examples of emotional political analogies. However, relating political issues to areas of knowledge that are closer to people's personal experiences might increase the likelihood of having a source with a strong emotional connotation. Analogy may be a powerful way of mapping emotional connotations on to previously neutral objects and events.

In summary, this study has provided interesting findings concerning how analogies are used in a specific naturalistic domain: politics. Analogy use was frequent, and over three-quarters of the analogies used were taken from domains other than politics. We have argued that the type of audience that the politicians and journalists were anticipating was a major factor in the selection of source analogs. Furthermore, the emotional connotation of the source analogs may also lead to the selection of a majority of nonpolitical analogies. Evidently, this study raises many questions, particularly concerning the effects of these analogies on the audience. Future research will focus the effect of these analogies on people's reasoning about the target problem.

\section{REFERENCES}

Blanchette, I., \& Dunbar, K. (2000). How analogies are generated: The roles of structural and superficial similarity. Memory \& Cognition, 28, 108-124.

Clement, C. A., Mawby, R., \& Giles, D. E. (1994). The effects of manifest relational similarity on analog retrieval. Journal of Memory \& Language, 33, 396-420.

DunBAR, K. (1995). How scientists really reason: Scientific reasoning in real-world laboratories. In R. J. Sternberg \& J. E. Davidson (Eds.), The nature of insight (pp. 365-395). Cambridge, MA: MIT Press.

DunBAR, K. (1997). How scientists think: Online creativity and conceptual change in science. In T. B. Ward, S. M. Smith, \& S. Vaid (Eds.), Conceptual structures and processes: Emergence, discovery and change (pp. 461-493). Washington, DC: American Psychological Association.

Edwards, R, \& Clevenger, T. (1990). The effect of schematic and affective processes on metaphorical invention. Journal of Psycholinguistic Research, 19, 91-102.

ERICSSON, A., \& J. SMITH (1991). Toward a general theory of expertise: Prospects and limits. Cambridge: Cambridge University Press.

Forbus, K. D., Gentner, D., \& LAW, K. (1994). MAC/FAC: A model of similarity-based retrieval. Cognitive Science, 19, 141-205.

Gentner, D., \& Markman, A. B. (1997). Structure mapping in analogy and similarity. American Psychologist, 52, 45-56.

Gentner, D., Rattermann, M. J., \& Forbus, K. (1993). The roles of similarity in transfer: Separating retrievability from inferential soundness. Cognitive Psychology, 25, 524-575.

Gick, M. L., \& Holyoak, K. J. (1980). Analogical problem solving. Cognitive Psychology, 12, 306-355.
GiLovich, T. (1981). Seeing the past in the present: The effect of associations to familiar events on judgments and decisions. Journal of Personality \& Social Psychology, 40, 797-808.

Glaser, J., \& Salovey, P. (1998). Affect in electoral politics. Personality \& Social Psychology Review, 2, 156-172.

Holyoak, K. J., \& Thagard, P. (1995). Mental leaps: Analogy in creative thought. Cambridge, MA: MIT Press.

Holyoak, K. J., \& Thagard, P. (1997). The analogical mind. American Psychologist, 52, 35-44.

Hummel, J. E., \& Holyoak, K. J. (1997). Distributed representations of structure: A theory of analogical access and mapping. Psychological Review, 104, 427-466.

KeAne, M. (1987). On retrieving analogues when solving problems. Quarterly Journal of Experimental Psychology, 39, 29-41.

Khong, Y. F. (1992). Analogies at war: Korea, Munich, Dien Bien Phu, and the Vietnam decisions of 1965. Princeton: Princeton University Press.

Kristiansen, C. M., \& Zanna, M. P. (1994). The rhetorical use of values to justify social and intergroup attitudes. Journal of Social Issues, 50, 47-65.

LAKOFF, G. (1991). Metaphor in politics: An open letter to the Internet from George Lakoff. Available: http://darkwing.uoregon.edu/ rohrer/ lakoff-1.htm

LAKOFF, G. (1993). The contemporary theory of metaphor. In A. Ortony (Ed.), Metaphor and thought (2nd ed., pp. 202-251). Cambridge: Cambridge University Press.

LAKOFF, G., \& Johnson, M. (1987). The metaphorical logic of rape. Metaphor \& Symbolic Activity, 2, 73-79.

Novick, L. R. (1988). Analogical transfer, problem similarity, and expertise. Journal of Experimental Psychology: Learning, Memory, \& Cognition, 14, 510-520.

Rohrer, T. (1991). To plow the sea: Metaphors for regional peace in Latin America. Metaphor \& Symbolic Activity, 6, 163-181.

RoHrer, T. (1995). The metaphorical logic of (political) rape: George Bush and the new world order. Metaphor \& Symbolic Activity, 10, 113-131.

Ross, B. H. (1989). Distinguishing types of superficial similarities: Different effects on the access and use of earlier problems. Journal of Experimental Psychology: Learning, Memory, \& Cognition, 15, 456468.

Shimko, K. L. (1994). Metaphors and foreign policy decision making. Political Psychology, 15, 655-671.

Spellman, B. A., \& Holyoak, K. J. (1993). An inhibitory mechanism for goal-directed analogical mapping. In R. Ashwin \& K. Eiselt (Eds.), Proceedings of the Fifteenth Annual Conference of the Cognitive Science Society (pp. 947-952). Hillsdale, NJ: Erlbaum.

Spellman, B. A., \& Holyoak, K. J. (1996). Pragmatics in analogical mapping. Cognitive Psychology, 31, 307-346.

Thagard, P., \& Shelley, C. P. (in press). Emotional analogies and analogical inference. In D. Gentner, K. H. Holyoak, \& B. Kokinov (Eds.), Analogy: Interdisciplinary perspectives. Cambridge, MA: MIT Press.

Vosniadou, S., \& Ortony, A. (1989). Similarity and analogical reasoning. Cambridge: Cambridge University Press.

Voss, J. F., Kennet, J., Wiley, J., \& Schooler, T. Y. (1992). Experts at debate: The use of metaphor in the U.S. Senate debate on the Gulf Crisis. Metaphor \& Symbolic Activity, 7, 197-214.

Wharton, C. M., Holyoak, K. J., Downing, P. E., \& Lange, T. E. (1994). Below the surface: Analogical similarity and retrieval competition in reminding. Cognitive Psychology, 26, 64-101.

(Manuscript received February 2, 2000; revision accepted for publication March 8, 2001.) 